\title{
Study on NGOs Participating in the Production of Public goods in Anti-poverty
}

\author{
Yaping Mao \\ Institute of Marxism \\ Kunming Metallurgy College \\ Kunming, China 650033
}

\begin{abstract}
This paper proposes to focus anti-poverty funds on the provision of public goods in view of the overall lack of funds for government anti-poverty. Through the introduction and role analysis of NGO organizations, it is proposed to strengthen the cooperation with NGOs in the guidance of the government in the provision of public goods to improve the efficiency of anti-poverty.
\end{abstract}

\section{Keywords-anti-poverty; public goods; NGOs}

\section{INTRODUCTION}

China is one of the countries with prominent problems in poverty and development in the world. Large-scale policy intervention is the characteristics and advantages of China's rural anti-poverty, and has made great achievements. After the reduction of the poverty-stricken population in the past, some fundamental changes have taken place in the existing poverty situation of ethnic minorities. In this context, we need to adjust strategic focus of the government's intervention in rural anti-poverty from the perspectives of form and content.

In the case that the government has a comprehensive poverty alleviation plan, and there is a shortage of capital investment, if the anti-poverty goal is achieved by focusing on each other, the income can be relatively maximized. Due to the large number of poor people and poverty-stricken areas that need to be supported, the poverty alleviation funds are relatively limited, the contradiction between supply and demand of funds leads to the difficulty in concentrating the use of funds. Inevitably, there is an average distribution. The investment focus is not prominent, and the funds are scattered. The scale merit of poverty alleviation funds cannot be achieved. In the end, poverty alleviation can only be short-term behavior due to the shortage of funds, leading to serious shortage of development in poverty alleviation areas. The current state finance cannot achieve a large amount of value-added in the short term. Under the established budget constraints, it may be considered to change the allocation pattern of the antipoverty funds for direct investment in productive investment. We can focus on the provision of public goods.

\section{KEY FIELDS OF GOVERNMENT ANTI-POVERTY SHOULD Be THE PROVISION OF PUBLIC GoOdS}

The so-called public goods are concepts against private goods, which refer to non-exclusive and non-competitive items. They are mainly to meet the public needs of members of society. In American scholar Samuelson's opinion, the interests of public goods are inextricably spread to all members of society, regardless of whether the individual wants to buy such public goods. The interests of these goods and services are shared by members of society and cannot be used by anyone. It can be expressed in the form of material and service. [1] With non-exclusive and noncompetitive characteristics, it supplies the same quantity and quality of goods to each member of society, and does not increase the marginal cost or crowd out others because of the number of consumers.

There are also quasi-public items with non-exclusive or non-competitive characteristics (also mixed public goods) existing between public goods and personal items. In 1997, the World Bank report stated that the government's function is to provide public goods and public services, including the provision of pure public goods (such as national defense, environmental protection, basic education, public health, social welfare, etc.), as well as the provision of mixed public goods, such as infrastructure and public utilities development [2].

Starting from the theme of this paper, public goods in poverty-stricken areas mainly include infrastructure construction (including roads, electricity, communications) and human capital investment (education, science and technology, culture, medical security). Since these items have strong externalities, that is, costs and benefits are imposed on others. This benefit is not reflected in currency or market transactions. It should be provided by the government.

The government's lack of public goods is one of the causes of poverty. Especially in China, the reason for the urban-rural gap is that the advancement of certain measures has led to the dual structure, including the uneven distribution and planning of public goods. The World Bank also points out that under the market economy route, some public goods and services have increasingly realized the charging system. In the case of increasing income gaps, 
relying on the charging of users to public services financing has increasingly hindered the necessary service of lowincome people. This means that economic development has made the poor population lose their fair opportunities and capabilities. From previous analysis, in order to promote fairness and social stability, it is reasonable to provide more solid public goods services for the poor. Specifically, these public goods that need to be provided are infrastructure, education, science and technology, and health services around human capital investments.

Second, the traditional government only provides homogenous public services. To a certain extent, it ignores the differences in citizen preferences. [3] Supply lacks local democracy. The top-down administrative system corresponds to the top-down supply mechanism of goods. The goal is mainly to meet the utility of the government and officials. At the same time, it should be influenced by the higher-level instructions without pursuing utility maximization of grassroots groups. The personal preference of officials affects the public product decisions, and the multi-level hierarchical structure does not respond to public needs in a timely and effective manner. The cost of government agencies also offsets the efficiency gains brought by centralization. Therefore, from the perspective of improving efficiency and fairness, it is necessary to make distinction between the supply and production functions of government public goods.

\section{NgOs Participate IN The Production OF Public} Goods

Non-governmental organizations generally refer to nongovernmental, non-profit, and voluntary social intermediary organizations dedicated to public welfare. Since the 1980s, NGOs have played an increasingly important role in the socio-economic development of countries around the world, and are regarded as the third sector outside the corporate and national institutional governments. The United Nations defines NGOs as non-profit, voluntary citizen organizations organized at the local, national, or international level. They provide a wide range of services and play a humanitarian role, reflecting the concerns of citizens, monitoring policies and encouraging political participation at the community level. They provide analysis and expertise as an early warning mechanism. The World Bank defines that "any NGOs, as long as its purpose is to help the poor, safeguard the rights of the poor, protect the environment, provide basic social services or promote community development. It can be called NGOs". [4] Starting from China's national conditions, non-governmental organizations refer to nonofficial, non-profit professional organizations that maintain a certain distance from government departments and business organizations. They usually carry out activities around the requirements of specific fields or classes.

In a sense, the government's inaction will have a profound impact on society as its action. As mandatory institutional arrangement, the state is the most powerful tool for protecting individual rights and the biggest and most dangerous aggressor of individual rights. If the boundaries of power between inaction and action are not defined, the government may also change from an asylum seeker of personal interests to an aggressor whose personal power is incapable of resisting. The government is also an economic man in reality, and there are also rationalities in pursuit of maximizing self-interest in behavior. And the government also considers the gains and losses of their own interests. Under the constraints of the established anti-poverty funds, the country does not have the possibility of pursuing the allround development of poverty-stricken areas. It should focus on improving the capacity of the poor groups, divesting its production functions, and bringing these functions to the market and implementing autonomous operations, enterprise management, and the supply of public goods. The government in the state system cannot effectively allocate social resources (government failure). The enterprises in the market system are not willing to provide public goods (market failures). Under the double "failure", the introduction of the third sector can integrate the current poverty alleviation resources in the country. As a new resource allocation system, NGOs can make up for the shortcomings of government and private enterprises. Especially, when the leading department of anti-poverty in China is the government, the poor have not yet formed a fully interactive relationship with the government, and the information is in an asymmetrical state. It is necessary to strengthen the supervision of relevant government work. On the other hand, based on the limitations of the government's own financial resources and the limitations of efficiency, the status quo of supporting socially disadvantaged groups with limited social support cannot be changed in a short period of time. Only by adjusting the relationship between the government and society can achieve greater results. The government is a provider of public goods. However, it does not mean that the government must be a producer of public goods. Some public products can be produced by enterprises, which is more efficient. Since the 1990s, the third sector has become an emerging force that is both differentiated and related to market regulation and government intervention.

Non-governmental organizations are the core elements of civil society, and their rise and activity are the manifestation of the subjective power of civil society. Civil society advocates that social management mode should focus on the governance rather than government. Governance is a process of contradictory subject and different interest groups adopting joint action and continuous action. It is an interactive process. In governance, authority is required. However, it is not necessarily a government agency. The degree of power operation is not top-down, but a process of interaction. [5] It emphasizes that citizens should be granted the right to express their opinions in an independent way without being suppressed, threatened or influenced by others or any dominant authority. Citizens should form public authority with the government to jointly govern the country. Non-governmental organizations and private organizations should participate in the provision of public services.

NGOs are free to engage in public welfare activities outside the system. They are relatively independent and non-governmental. They do not represent the government or 
the state. They express the demands of the people. They are closer to the public in terms of spatial distance. The actions and decisions of NGOs are based on the various established conditions of the locality. The staff has greater autonomy, and can adapt to the environment to make the adjustment. This is related to the government's anti-poverty information mainly from strong economic growth motives. The plan is formulated in a top-down manner, and it does not necessarily understand the local situation. They regard the provision of public welfare and public services as their main goal, rather than pursuing profits. In the politics, management and finance, they are independent from the government to a certain extent. The public information can be quickly responded and communicated to the government to avoid government inefficiency. NGOs also have a greater tendency toward socially disadvantaged groups. Their members participate in organizations that are completely voluntary rather than forced. These organizations have nonparty and non-religious characteristics. Volunteers have demonstrated their volunteerism and emphasized the participation of the benefit group. This participation includes the formulation, implementation and supervision of development projects. The project can be combined with local culture. The face-to-face work model can be used for policy interpretation and policy implementation to individual and minority. The beneficiary can get concrete help according to his own situation. Thus, they will become tools for the vulnerable groups to express their will and maintain the fairness of the government and the vulnerable groups. In addition, the scope of NGO work is generally small and single. The work is professional. It can concentrate on responsible intervention. Most of the staff are volunteers with better education, and can accept new ideas and methods. Due to the clear objectives and frequent volunteer work at the grassroots level, the delivery channels are smoother. The information can timely receive feedback, and the work accuracy is higher.

\section{COOPERATION BETWEEN THE GOVERNMENT AND NGOS IN THE FIELD OF PUBLIC GOODS}

Between an active government and a vulnerable poor entity, NGOs are the intermediary that balances the interests of government and vulnerable poor entity and effectively communicates information. The participation of NGOs in combating poverty is supervision and promotion of the government. Its working mode, professionalism and volunteerism are the reference for government work. The public can clearly assess the efficiency of both, promoting the government's work. In the course of project practice, most of them have their own professions. In some fields, they have achieved the successful achievements that the government can't achieve.

In order to effectively use the NGO model, it is necessary to solve the dual management system for NGOs - NGO registration management agency and the business supervisory unit respectively exercise the supervision and management functions to NGOs. The NGO registration management agency is the registration management organ of the civil affairs system at all levels. The NGO business management unit is a government functional department or a government-authorized unit related to the business scope of the non-governmental organization. This system is generally not conducive to the development of NGO. Excessive emphasis on the approval of registration limits the legalization of NGOs, ignoring the development and supervision. The government should actively guide and strengthen the self-discipline mechanism of NGOs, and restore the relatively independent NGOs' status of NGOs. It can maintain the advantages of NGOs' flexible and efficient characteristics, and low-cost operation. To build a multidisciplinary civil evaluation system, we should also improve the government's normative ability and administrative capacity according to law. There are not simple relationships such as management and compliance, controlling and being controlled between the government and NGOs. There are negotiating relationships and cooperative relationships between the government and NGOs. Therefore, it is necessary to separate the political and social organizations as an important task of the government's transformation. We should transfer some public service and social public service functions to qualified NGOs as soon as possible. Secondly, NGOs can make the non-profit poverty alleviation affairs undertaken or implemented by the government. We can encourage NGOs to participate in the bidding system and the responsibility system to form "multiple synergies". [3] The government also needs to legalize the management of NGOs. Therefore, a balanced and cooperative relationship between the government and NGOs is established to provide a driving force and synergy for building a harmonious society.

\section{CONCLUSION}

The anti-poverty strategy is an important part of China's comprehensive construction of a well-off society in the future. It is also an important measure related to the national economy and people's livelihood and the realization of social fairness and justice. To complete this major strategic decision, we need the joint efforts of the government and social organizations, encourage the participation of the poor, and achieve the final result.

\section{REFERENCES}

[1] Zhang Liang, el at. "Introduction to Public Administration", Life and Reading, Xinzhi Sanlian Bookstore, 1998, p. 3.

[2] World Bank: 1997 World Development Report, China Financial and Economic Publishing House, 1997, p. 27.

[3] He Jinghua. "Distinction between Supply and Production: An Analysis Framework Based on the Realization of Government Public Service Functions", China Administration Management, No. 2, 2007.

[4] Wang Shaoguang. "Diversity and Unity - International Comparative Study on the Third Sector", Zhejiang People's Publishing House, 1999, p. 17.

[5] Yu Keping. "The rise of Chinese civil society and the change of governance", Social Sciences Academic Press, 2000, p. 189-196. 